\title{
Reversed L-type Matching Impedance of RF-to- DC Rectifier for Energy Harvesting System
}

\author{
Nuraiza Ismail and Ermeey Abd Kadir
}

\begin{abstract}
This paper presents the analysis of an RF energy harvesting system using a novel design of harvester antenna and wirelessly connected to reversed L-type matching impedance integrated with a 2 -stage rectifier circuit. The rectifier circuit is based on a voltage doubler-type topology comprising only two circuit components which are a capacitor and Schottky diode that are capable of receiving a $\mathrm{Wi}-\mathrm{Fi}$ input signal of $2.45 \mathrm{GHz}$ from a harvester antenna. The antenna design is a rectangular patch antenna that is based on a coplanar waveguide feed. The zero biased Schottky diode of the SMS7630 model is chosen for the rectification process where the low input signal of $-10 \mathrm{dBm}$ has successfully rectified the RF input power to the DC output voltage. The simulation results show that the 2-stage rectifier circuit needs impedance matching for a better DC output voltage with a good power conversion efficiency than a rectifier circuit without impedance matching for enabling low-power electronic devices.
\end{abstract}

Index Terms - RF-DC power conversion, coplanar waveguide, energy harvesting, rectifier circuit, impedance matching, Schottky diode.

\section{INTRODUCTION}

$\mathrm{E}$ NERGY harvesting is the conversion of energy from the surrounding environment or ambient into valuable electrical energy [1]-[3]. It has become a viable alternative to the conventional battery plug-in technique for powering lowpower electronic devices, which is commonly used in the Internet of Things (IoT) wireless sensor networks, wearable electronic devices, and implanted biomedical instruments [4], [5]. This technology utilizes energy from a variety of natural sources, including solar radiation, heat, vibration, piezoelectric energy, thermal energy and electromagnetic waves or radiofrequency, where the wireless power transmission technique is used for converting the energy to usable DC power [6], [7].

In recent decades, the utilization of the ambient environment as a source of energy harvesting through radio-frequency (RF) has increased significantly. This RF harvesting technique is the most significant one compared to other sources for its accessibility and ease of scavenging. Other sources are beyond human control since thermal energy necessitates the presence

This manuscript is submitted on 3th Jun 2021 and accepted on 23th August 2021. Nuraiza Ismail and Ermeey Abd Kadir are with the School of Electrical Engineering, College of Engineering, Universiti Teknologi MARA, 23000 Dungun, Terengganu (e-mail: nuraizaismail@gmail.com)

1985-5389/C 2021 The Authors. Published by UiTM Press. This is an open access article under the CC BY-NC-ND license (http://creativecommons.org /licenses/by-nc-nd/4.0/). of heat, vibration requires the presence of motion, and solar involves the presence of light [8], [9]. The concept of RF energy harvesting is based on capturing ambient energy, including wasted energy that is hovering in the surrounding environment, without causing any interruption to the environment. The systems consist of an antenna that receives an RF signal, a network that performs impedance matching to maximize power transfer from the antenna, and a rectifier circuit. The rectifier circuit is a crucial part of the system block that influences the efficiency of the system. It converts the RF signal to DC voltage and stores the energy in holding load storage devices such as capacitors and batteries. The fundamental block diagram of energy harvesting system is as depicted in Figure 1.

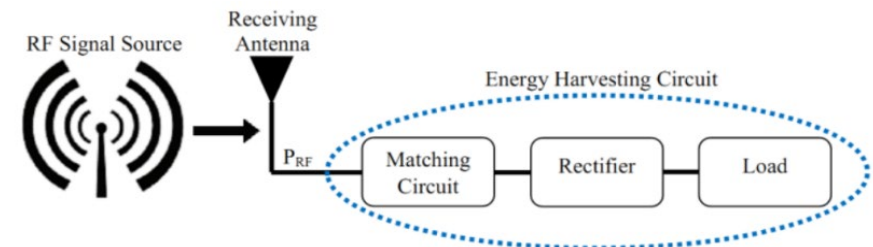

Fig. 1. The main part of the RF energy harvesting system [10].

The primary barrier in designing an RF energy harvesting system is to operate with a low-power RF signal, where the accessible ambient RF signal is significantly lower than $0 \mathrm{dBm}$. The research reported in [11], [12] obtained the maximum power conversion efficiency of the rectifier at relatively high input power levels, which is over $5 \mathrm{dBm}$. Among past studies in [13], [14] the most often employed method of achieving high maximum conversion efficiency is a multistage rectifier. Nonetheless, the high-power efficiency obtained is due to the high input RF power implemented by the multistage rectifier. For circuit optimization, the circuit proposed in [15] requires four stages in the rectifier arrangement when a $-15 \mathrm{dBm}$ input power signal is received. They discovered that increasing the rectifier stages did not improve efficiency for a low-power input signal. As the rectifier stage increases, the peak of the efficiency curve drops toward higher powers. Although the increasing number of stages gives higher voltage at the load terminal, the current reduces at the load terminal as the increasing stages [16], [17]. Since ambient RF energy harvesting occurs at high frequencies and requires operating with low-power RF signals, the Schottky diode has been widely employed for RF energy harvesting due to its low threshold 
voltage and fast switching diode speed [18]-[20]. In this proposed work, the design harvester antenna is integrated with a 2-stage rectifier circuit based on voltage doubler configuration. The design aims to convert the low input signal of $-10 \mathrm{dBm}$ within the 2.45 frequency band RF signal into functional DC voltage with a good power conversion efficiency. The $-10 \mathrm{dBm}$ input signal is based on the surrounding Wi-Fi coverage signal, as shown in Figure 2, where ambient energy is essential as a reference of input power (in $\mathrm{dBm}$ ) for the rectifier circuit, regardless of where the area is.

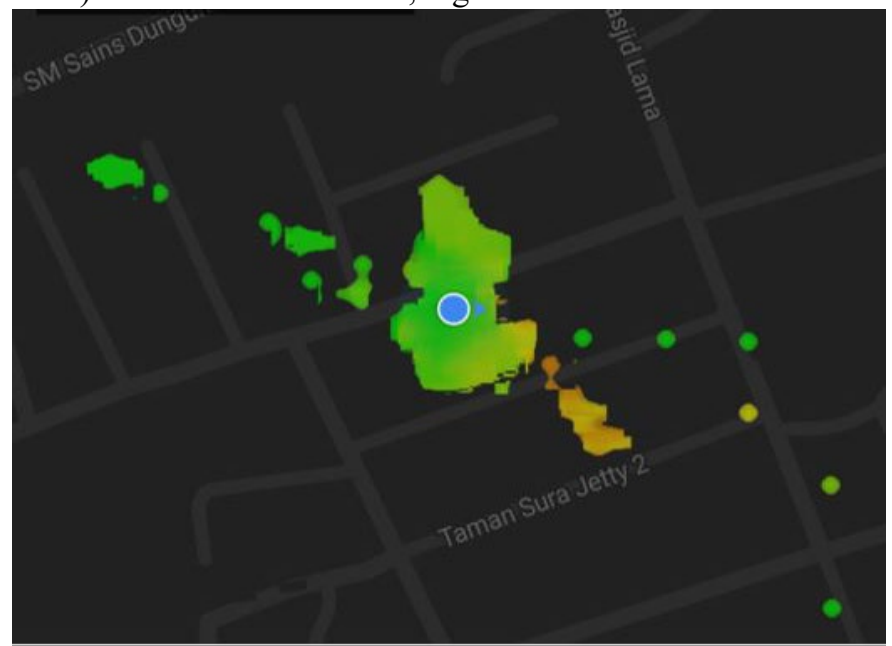

\section{Neza.2.4GHz@unifi 04:5e:a4:6d:90:b0}

$-10 \mathrm{dBm}$

\section{$2432 \mathrm{MHz}$ [WPA2-PSK-CCMP][ESS]}

Fig. 2. Wi-Fi coverage signal at $2.4 \mathrm{GHz}$ frequency as observed in Dungun, Terengganu area.

\section{HARVESTING ANTENNA}

An antenna is vital for harvesting RF energy in the receiving part, as it captures energy from the ambient and performs as a transducer between propagating and guided waves. The selection of the operating frequency is a significant aspect in designing an RF energy harvester. As shown in Figure 2, the ambient Wi-Fi signal is $2.4 \mathrm{GHz}$ and the resonant frequency is at $2.432 \mathrm{GHz}$. The industrial, scientific, and medical (ISM) band of $2.45 \mathrm{GHz}$ can be regarded as an excellent alternative for avoiding larger equipment and installation issues, as it offers a decent trade-off between signal attenuation, frequency and antenna size [21]. Hence, for this proposed antenna harvester, $2.45 \mathrm{GHz}$ is chosen as an operating frequency.

The proposed design of the antenna harvester is as depicted in Figure 3. Its antenna structure comprises a rectangular patch fed by an asymmetric $50 \Omega$ coplanar line. This design is chosen for its high circuit density and impedance matching simplicity on a single layer. Furthermore, its active and passive components are easy to integrate, as well as minimal dispersion and radiation loss. This makes the coplanar waveguide ideal in designing an antenna harvester.

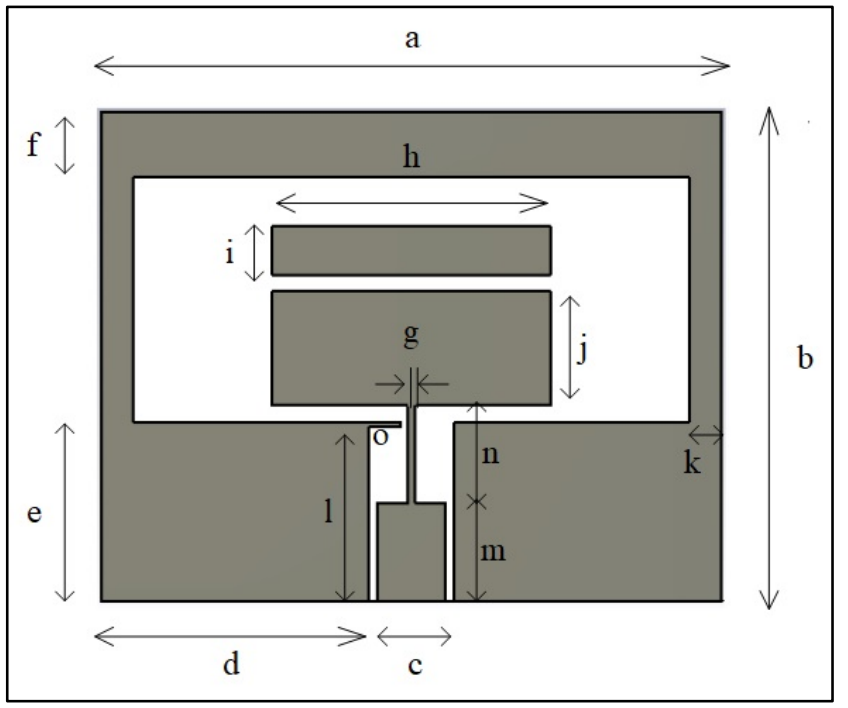

Fig. 3. Proposed antenna design fed by coplanar waveguide.

The proposed coplanar waveguide harvester antenna is designed using a low-cost FR-4 substrate with a dielectric constant $\varepsilon_{r}=4.3, \tan \delta=0.025$ and thickness of $1.6 \mathrm{~mm}$. The antenna area is $30 \times 38 \mathrm{~mm}^{2}$, where the width and length are obtained using (1) and (2), respectively. The optimization of the geometry structure of the proposed RF harvester antenna is listed in Table I.

$W=\frac{C}{2 f_{r}} \sqrt{\frac{2}{\varepsilon_{r}+1}}$

$L=\frac{C}{2 f_{r} \sqrt{\varepsilon_{r}}}$

$W=$ Width of the patch

$L=$ Length of the patch

$C=$ Speed of the light

$f r=$ Frequency

$\varepsilon_{r}=$ Dielectric medium permittivity

TABLE I

THE PROPOSED ANTENNA PARAMETERS

\begin{tabular}{cc}
\hline \hline Parameter & $(\mathrm{mm})$ \\
\hline $\mathrm{a}$ & 38 \\
$\mathrm{~b}$ & 30 \\
$\mathrm{c}$ & 4.235 \\
$\mathrm{~d}$ & 16.3825 \\
$\mathrm{e}$ & 11 \\
$\mathrm{f}$ & 4 \\
$\mathrm{~g}$ & 0.5 \\
$\mathrm{~h}$ & 17 \\
$\mathrm{i}$ & 3 \\
$\mathrm{j}$ & 7 \\
$\mathrm{k}$ & 2 \\
$\mathrm{l}$ & 10.7 \\
$\mathrm{~m}$ & 6 \\
$\mathrm{n}$ & 6 \\
$\mathrm{o}$ & 2 \\
\hline \hline
\end{tabular}




\section{RF HARVESTING CIRCUIT}

A rectifier circuit is essential in an RF energy harvesting system for converting the RF input signal into functional DC energy. The basic configuration of the proposed rectifier circuit is based on a single-stage voltage doubler that consists of two diodes and two capacitors, as shown in Figure 4. In most RF energy harvesting systems, the RF input power is deficient; therefore, the DC voltage harvested via a single-stage rectifier is insufficient. Consequently, the proposed circuit in this work is cascaded into two stages to get a higher DC voltage. Figure 5 indicates the circuit configuration of the rectifier for this work, which consists of four Schottky diodes, four capacitors, and a resistive load, where Figure 5(a) is the rectifier circuit without matching impedance. In contrast, Figure 5(b) includes a pair of inductors representing a reversed L-type matching impedance. The proposed rectifier circuit in this design uses a zero bias Schottky diode of the SMS7630 model. The selection of this zero bias diode model is not just due to it having a minimum threshold voltage and high switching diode speed, but also due to its slight parasitic power loss and low power dissipation in the matching network.

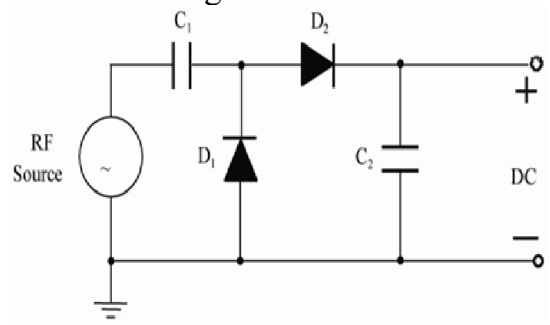

Fig. 4. The basic configuration of the rectifier which comprises two diodes and two capacitors for the rectification process[22].

The DC output voltage of the basic circuit configuration can be expressed as (3).

$$
V_{\text {output }}=\frac{V_{o c}}{R_{\text {int }}+R_{\text {load }}} \times R_{\text {load }}
$$

where $V_{o c}$ is the open-circuit voltage and $R_{\text {int }}$ is the internal resistance. As a result, when $n$ stages are implemented, the output voltage will be as (4).

$$
V_{\text {output }}=\frac{n V_{\text {oc }}}{n R_{\text {int }}+R_{\text {load }}} \times R_{\text {load }}
$$

The rectifier, which also functions as a converter circuit, transforms the AC power of the RF input signal. Since this RF source is received as a sine wave signal, this system requires $\mathrm{AC}$ to DC conversion. Thus, for circuit simulation, the input source, Vs is applied to the rectifier circuit in a sinusoidal form representing an RF signal of the antenna. LTSpice software is used to analyze the performance of the rectifier circuit in terms of output voltage and power conversion efficiency. The internal resistance is set at $50 \Omega$, which represents the antenna port impedance of the input terminal. In this work, the input power and the terminal load are set to $-10 \mathrm{dBm}$ and $10 \mathrm{k} \Omega$ respectively, for the $2.45 \mathrm{GHz}$ operating frequency.

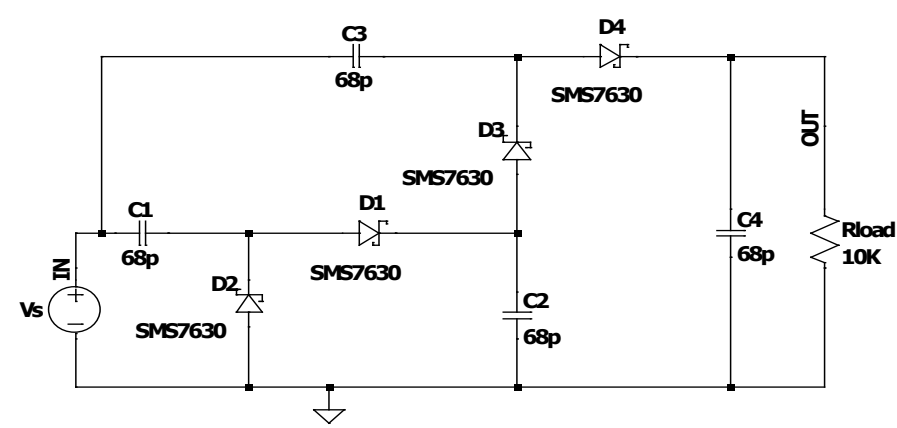

(a)

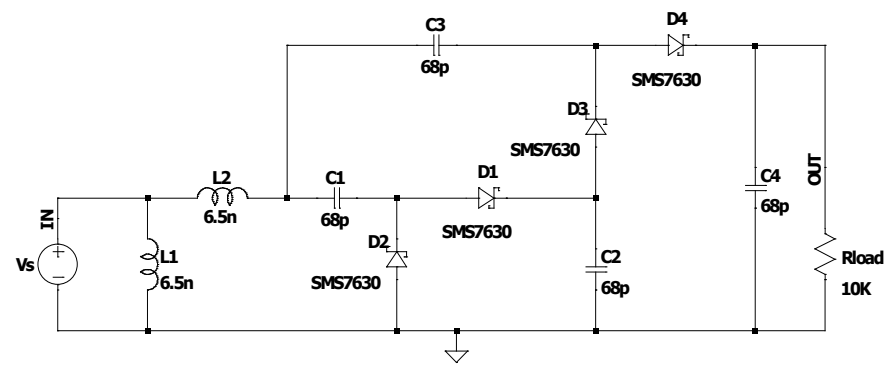

(b)

Fig. 5. Circuit diagram of the 2-stage RF-DC converter based on the voltage doubler circuit topology. (a) without matching impedance. (b) with reversed Ltype matching impedance.

\section{RESUlt AND Discussion}

The simulation results are discussed in two sections; the receiving antenna and the rectifier circuit design.

\section{A. Receiving Antenna}

The performance of the proposed antenna design has been simulated using CST Microwave Studio software in terms of return loss, line impedance, and antenna gain. Before integrating to the rectifier circuit, the proposed coplanar antenna is analyzed separately by evaluating the S-parameters. This is done to verify that the performance of the proposed antenna achieves a good return loss and gain with an ideal matching impedance of $50 \Omega$ at $2.45 \mathrm{GHz}$ frequency. Figure 6 indicates the perfect matching impedance is performed at 2.45 $\mathrm{GHz}$ with a good return loss, S11 of $-28.223 \mathrm{~dB}$. The operating bandwidth of $279.9 \mathrm{MHz}$ in the range between 2.3381 to 2.6180 $\mathrm{GHz}$ covers the IEEE 802.11 standard in the $2.45 \mathrm{GHz}$ wireless ISM band. Hence, the range successfully covers the ambient resonating frequency of $2.432 \mathrm{GHz}$, as shown in Figure 2 (refer to section I).

The good value of $S_{11}$ does not signify that an antenna is wellradiated. The antenna gain is an important parameter that must be taken into account when designing an antenna. The gain of an antenna indicates how much energy is transmitted in the direction of peak directivity compared to radiated power. The gain for this work is $3.89 \mathrm{dBi}$, as depicted in the far-field radiation pattern in Figure 7 . The dipole antenna has an elevation plane beamwidth of $88.8^{\circ}$ with an omnidirectional radiation pattern. The proposed coplanar waveguide antenna radiates in both the front and rear directions since all metal patches of the substrate are constructed on a single side. 


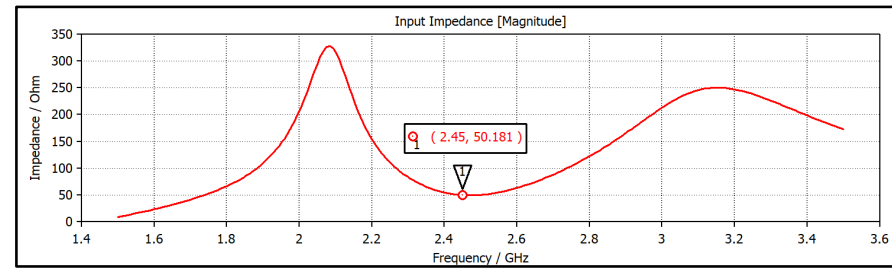

(a)

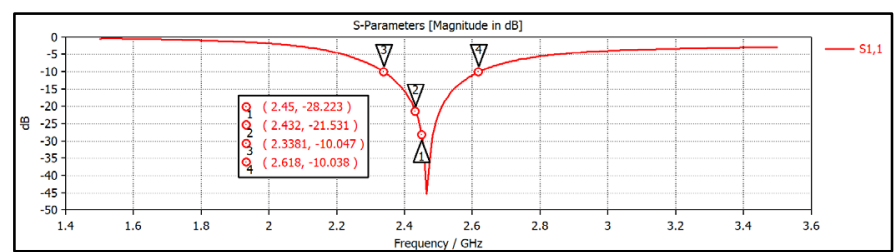

(b)

Fig. 6. Simulation results of the proposed coplanar waveguide antenna. (a) Perfectly matched line impedance at $2.45 \mathrm{GHz}$ (b) Return loss of -28.223 $\mathrm{dB}$ at $2.45 \mathrm{GHz}$ and -21.531 at $2.432 \mathrm{GHz}$ frequency.

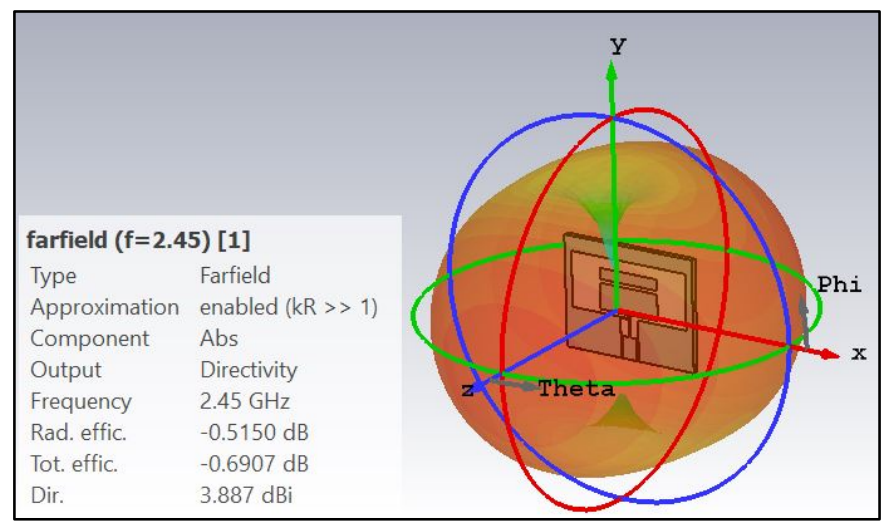

(a)

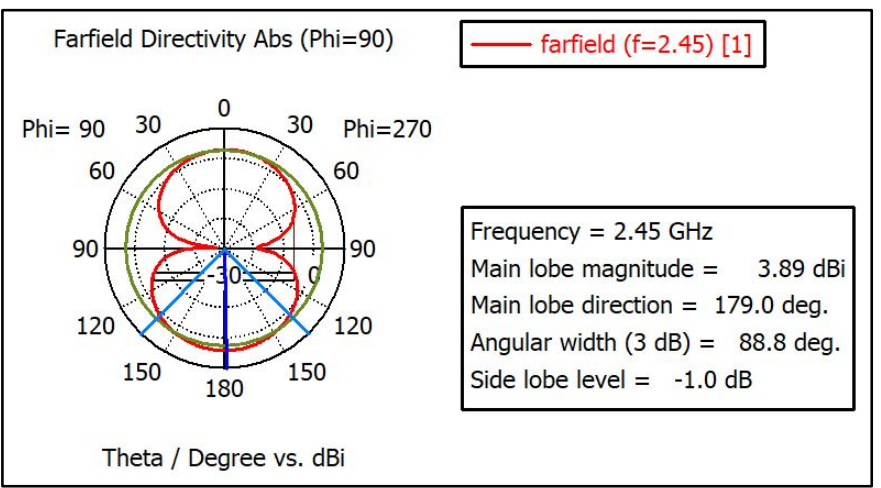

(b)

Fig. 7. The simulated far-field radiation pattern of the coplanar waveguide antenna. (a) 3-D pattern. (b) 2-D pattern.

\section{B. Rectifier Circuit}

The performance of the proposed rectifier circuit that includes reversed L-type matching impedance has been analyzed in terms of output voltage and power conversion efficiency. The results are compared between the circuit with and without matching impedance to evaluate how the inserted matching impedance affected the circuit performance. It is seen in Figure 8 that the circuit with reversed L-type matching impedance gives a higher output voltage and power conversion efficiency than the circuit without matching impedance.

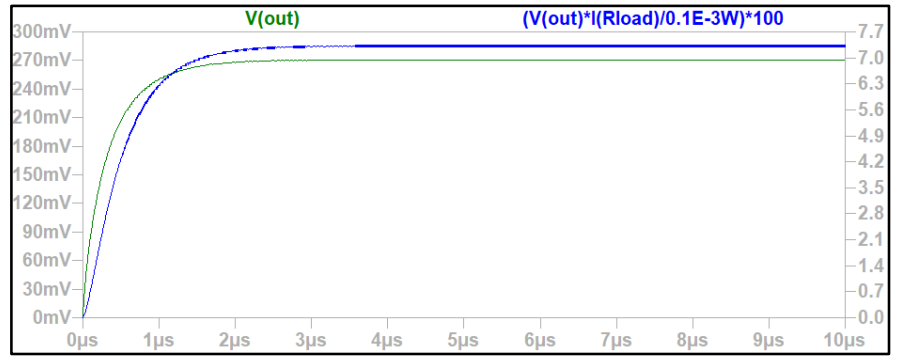

(a)

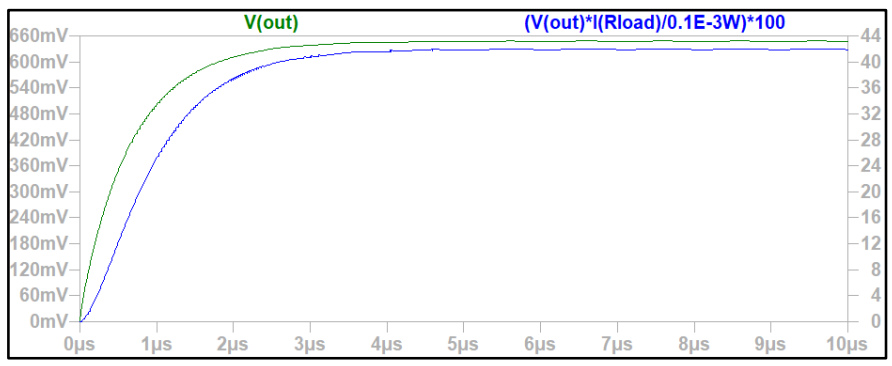

(b)

Fig. 8. Rectified DC voltage and RF-DC conversion efficiency of rectifying circuits for RF input power of $-10 \mathrm{dBm}$ simulated at $2.45 \mathrm{GHz}$ (a) without matching impedance. (b) with reversed L-type matching impedance.

TABLE II

PERFORMANCE COMPARISON BETWEEN INSERTED L-TYPE MATCHING IMPEDANCE AND WITHOUT MATCHING IMPEDANCE

\begin{tabular}{ccc}
\hline \hline Rectifier & $\begin{array}{c}\text { Without } \\
\text { matching }\end{array}$ & $\begin{array}{c}\text { Reverse } \\
\text { L-type }\end{array}$ \\
\hline Circuit & 270 & 648 \\
Output Voltage [mV] & 1.35 & 3.24 \\
Voltage gain & 7.3 & 42.0 \\
Conversion efficiency (\%) & 2.5 & 14.3 \\
Energy [pJ] & \\
\hline \hline
\end{tabular}

Table II summarizes the performance for both types of circuits. The results demonstrate that, by inserting reversed Ltype impedance matching, the proposed rectifier circuit's conversion efficiency and energy storage are six times greater than without impedance matching. Hence, for maximum power transfer, an impedance matching network is essential for matching rectifier and antenna impedance.

\section{S-Parameter Analysis}

The antenna and rectifier circuit is connected to maximize the stored energy. The S-parameter findings are used to examine the signal performance of the rectifier circuit in relation to circuit component values discrepancies. Since the rectifier circuit with matching impedance has shown good performance compared to the rectifier without matching impedance, the rectifier with reversed L-type matching impedance is integrated with the proposed antenna. Figure 9 indicates the integration between the coplanar waveguide antenna and the rectifier circuit using CST Microwave Studio incorporated with CST Design Studio and the results after integration. The results show an excellent agreement for both return losses, $\left|\mathrm{S}_{11}\right|=0.13301$ and transfer coefficient $\left|\mathrm{S}_{21}\right|=$ 0.5631 at $2.45 \mathrm{GHz}$ operating frequency since the magnitude value of $\left|S_{11}\right|$ and $\left|S_{21}\right|$ is ideal to be close to 0.1 and 1 respectively. 


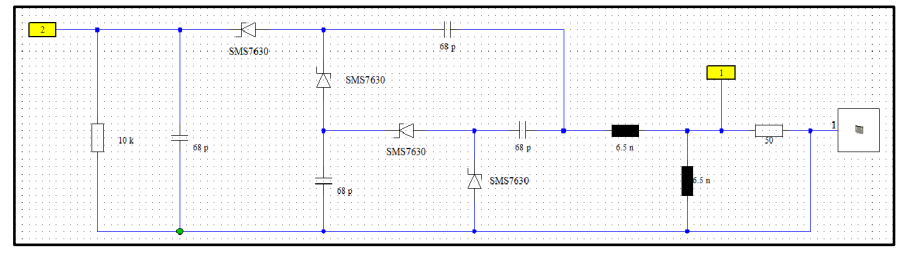

(a)

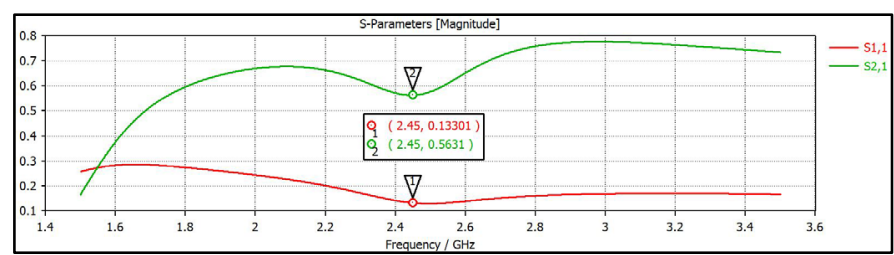

(b)

Fig. 9. The combination of the proposed coplanar waveguide antenna and rectifier circuit with reversed L-type matching impedance. (a) Circuit connection (b) The circuit return loss $\left|S_{11}\right|$ and transfer coefficient $\left|S_{21}\right|$.

\section{Comparison with Previous Work}

The summary in Table III outlines the implemented rectifier strengths and weaknesses compared to previous researchers' work. Various considerations include rectifier type, input voltage and power level, output voltage, load resistance, and conversion efficiency for comparison. This study has shown this work to be most efficient at the input power level of -10 $\mathrm{dBm}$ in comparison with the prior work in [23]-[25]. A 5-stage HSMS2820 Schottky diode voltage doubler implemented in [26] has a higher output voltage which is almost three times larger than this work. However, the load resistance used is too small and the 5-stage proposed circuit is much more costly. The work in [27] and [28] has reported higher efficiency than this work because of the implemented PMOS-NMOS and multistage with a cascade voltage multiplier. Nevertheless, the value of load resistance used in both works is smaller compared to this work. In a low input power level, the load resistance affects the power conversion efficiency as low load resistance gives high efficiency, which can be proved using equation (5).

$$
\eta \%=\frac{\mathrm{V}_{\text {out }}{ }^{2}}{\mathrm{P}_{\mathrm{RF}} \mathrm{R}_{\text {Load }}} \times 100 \%
$$

\section{CONCLUSION}

In this work, a rectifier with reversed L-type matching network has been implemented as a passive voltage boosting circuit. The circuit performance has been compared with the 2stage rectifier circuit without impedance matching to analyze the effect of the matching network. The rectifier circuit indicates that the input power can be rectified up to $0.65 \mathrm{DC}$ signal with the power conversion efficiency of $42 \%$ at a low ambient input power of $-10 \mathrm{dBm}$. The reliability of this rectifier circuit for RF energy harvesting is demonstrated by integrating with the coplanar waveguide antenna. The results have shown a good return loss and transfer coefficient performance applicable to the $2.45 \mathrm{GHz}$ ISM band. As a result, a matching network is required to ensure maximum power transfer occurs between the harvesting antenna and the rectifier circuit.

TABLE III

PERFORMANCE SUMMARY AND COMPARISON WITH RELATED WORKS

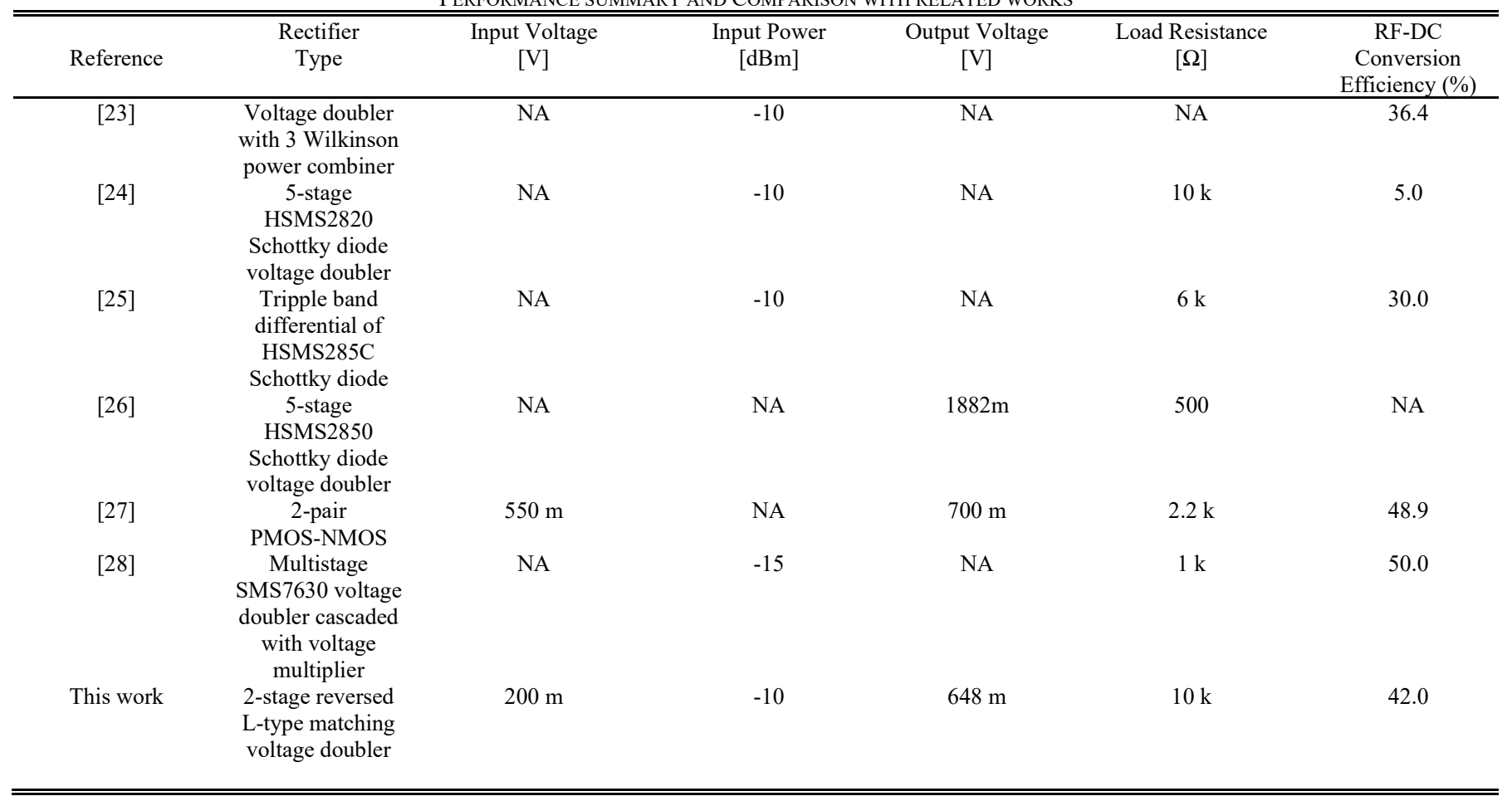




\section{REFERENCES}

B. S. Kim et al., "Ambient RF Energy-Harvesting Technologies for Self-Sustainable Standalone Wireless Sensor Platforms," Proc. IEEE, vol. 102, no. 11, 2014.

[2] T. A. Elwi and H. S. Ahmed, "A UWB Monopole Antenna Design based RF Energy Harvesting Technology," 2018 Third Sci. Conf. Electr. Eng., pp. 111-115, 2018.

[3] R. Ren, J. Huang, and H. Sun, "Investigation of Rectenna's Bandwidth for RF Energy Harvesting," 2020 IEEE MTT-S Int. Microw. Work. Ser. Adv. Mater. Process. RF THz Appl. IMWS-AMP 2020 - Proc., 2020.

[4] D. D. Mhudil et al., "Ambient RF Energy Harvesting for Dual-Band frequencies below $6 \mathrm{GHz}$," 2018 IEEE Wirel. Power Transf. Conf., pp. 6-9, 2018.

[5] H. Bhamra, S. Member, Y. Huang, and Q. Yuan, "An Ultra-Low Power 2 . $4 \mathrm{GHz}$ Transmitter for Energy Harvested Wireless Sensor Nodes and Biomedical Devices," vol. 7747, no. 208927, pp. 10-14, 2020.

[6] J. T. Kim, B. R. Heo, and I. Kwon, "An energy-efficient uwb transmitter with wireless injection locking for rf energy-harvesting sensors," Sensors, vol. 21, no. 4, pp. 1-16, 2021.

[7] K. Ishibashi, J. Ida, L. T. Nguyen, R. Ishikawa, Y. Satoh, and D. M. Luong, "RF Characteristics of Rectifier Devices for Ambient RF Energy Harvesting," Proceeding - 2019 Int. Symp. Electron. Smart Devices, ISESD 2019, pp. 7-10, 2019.

[8] I. Adam, M. N. M. Yasin, M. E. A. Aziz, and M. I. Sulaiman, "Rectifier for RF energy harvesting using stub matching," Indones. $J$. Electr. Eng. Comput. Sci., vol. 13, no. 3, pp. 1007-1013, 2019.

[9] S. Keyrouz, H. J. Visser, and A. G. Tijhuis, "Rectifier analysis for Radio Frequency energy harvesting and Power Transport," pp. 428431, 2012.

[10] N. Ismail and E. A. Kadir, "A Rectification Circuit with Co-Planar Waveguide Antenna for $2.45 \mathrm{GHz}$ Energy Harvesting System," Adv. Sci. Technol. Eng. Syst. J., vol. 6, no. 2, pp. 984-989, 2021.

[11] S. Kim et al., "A -20 to $30 \mathrm{dBm}$ Input Power Range Wireless Power System with a MPPT-based Reconfigurable $48 \%$ Efficient RF Energy Harvester and $82 \%$ Efficient A4WP Wireless Power Receiver with Open Loop Delay Compensation," Trans. Power Electron., vol. 8993, no. c, pp. 1-31, 2018.

[12] W. Liu, K. Huang, S. Member, and T. Wang, "A Broadband HighEfficiency RF Rectifier for Ambient RF Energy Harvesting," IEEE Microw. Wirel. Components Lett., vol. 30, no. 12, pp. 50-53, 2020.

[13] N. Pournoori, M. W. A. Khan, L. Ukkonen, and T. Björninen, "RF Energy Harvesting System Integrating a Passive UHF RFID Tag as a Charge Storage Indicator," 2018 IEEE Antennas Propag. Soc. Int. Symp. Usn. Natl. Radio Sci. Meet. APSURSI 2018 - Proc., pp. 685686, 2018.

[14] M. M. Mansour, S. Yamamoto, H. Kanaya, and S. Member, "Reconfigurable Multistage RF Rectifier Topology for $900 \mathrm{MHz}$ ISM Energy-Harvesting Applications," IEEE Microw. Wirel. Components Lett., vol. 30, no. 12, pp. 1-4, 2020.

[15] U. Muncuk, K. Alemdar, J. D. Sarode, and K. R. Chowdhury, "Multiband ambient RF energy harvesting circuit design for enabling batteryless sensors and IoT," IEEE Internet Things J., vol. 5, no. 4, pp. 2700-2714, 2018.

[16] M. M. Al-Azawy and F. Sari, "Analysis of Dickson Voltage Multiplier for RF Energy Harvesting," Proc. - 2019 IEEE 1st Glob. Power, Energy Commun. Conf. GPECOM 2019, pp. 10-14, 2019.

[17] D. Misra, G. Das, and D. Das, "An IoT based Wireless Energy Harvesting using Efficient Voltage Doubler Stages in a RF to DC Converter," 2018 4th Int. Conf. Comput. Commun. Autom., pp. 1-5, 2019.

[18] K. Shafique et al., "Energy Harvesting Using a Low-Cost Rectenna for Internet of Things (IoT) Applications," IEEE Access, vol. 6, pp. 30932-30941, 2018.

[19] Q. M. Dinh and M. T. Le, "Ambient RF energy harvesting system based on wide angle metamaterial absorber for battery-less wireless sensors," Int. Conf. Adv. Technol. Commun., vol. 2020-Octob, pp. 140-144, 2020.

[20] A. Mouapi, N. Hakem, and N. Kandil, "A Performance Analysis of Schottky Diode to support RF Energy Harvesting," pp. 1169-1170, 2019.

[21] M. Latrach, "A miniaturized printed rectenna for wireless RF energy harvesting," Int. J. Electron. Commun. Regul. Pap., vol. 127, no.
October, 2020.

[22] J. C. S. Kadupitiya, T. N. Abeythunga, P. D. M. T. Ranathunga, and D. S. De Silva, "Optimizing RF energy harvester design for low power applications by integrating multi stage voltage doubler on patch antenna," 2015 8th Int. Conf. Ubi-Media Comput. UMEDIA 2015 - Conf. Proceeedings, pp. 335-338, 2015.

[23] A. Sedeek, E. Tammam, and E. S. Hasaneen, "Design of an efficient $2.45 \mathrm{GHz} \mathrm{RF}$ rectifier for energy harvesting from low RF power density environment," Proc. 2020 Int. Conf. Innov. Trends Commun. Comput. Eng. ITCE 2020, pp. 268-271, 2020.

[24] T. Sathiyapriya, V. Gurunathan, T. Vimala, K. N. K. Prasad, and T. N. Kumar, "Voltage doubler design for RF energy harvesting system," 2020 7th Int. Conf. Smart Struct. Syst. ICSSS 2020, pp. 3639, 2020.

[25] S. Chandravanshi, S. Sen Sarma, and M. J. Akhtar, "Design of Triple Band Differential Rectenna for RF Energy Harvesting," IEEE Trans. Antennas Propag., vol. 66, no. 6, pp. 2716-2726, 2018.

[26] D. Misra, G. Das, and D. Das, "An IoT based wireless energy harvesting using efficient voltage doubler stages in a RF to DC converter," 2018 4th Int. Conf. Comput. Commun. Autom. ICCCA 2018, pp. 1-5, 2018.

[27] W. W. Y. Lau and L. Siek, "A $2.45 \mathrm{GHz}$ CMOS rectifier for RF energy harvesting," 2016 IEEE Wirel. Power Transf. Conf. WPTC 2016, pp. 1-3, 2016.

[28] M. M. Mansour and H. Kanaya, "High-Efficient Broadband CPW RF Rectifier for Wireless Energy Harvesting," IEEE Microw. Wirel. Components Lett., vol. 29, no. 4, pp. 288-290, 2019. 